\title{
ChARACTERIZATION OF GLUTAMATERGIC PhENOTYPES IN hYBRID SEPTAL NEUROBLASTOMA (SN56) CELLS
}

\author{
Luis F. Pachecol \\ M. Velazquez ${ }^{l}$ \\ M. Villarreal ${ }^{l}$ \\ J. Rodriguez ${ }^{1}$ \\ Boris Ermolisnky ${ }^{1.2}$ \\ Emilio R. Garrido-Sanabrial,
}

\begin{abstract}
Septal Neuroblastoma (SN 56) cells are hybrid cells made through cell fusions between quiescent medial septum neurons (cholinergic) and tumoral neuroblastoma cells. Cholinergic cells synthesize and release the neurotransmitter acetylcholine. Preliminary studies in our laboratory revealed that SN56 neurons also express the vesicular glutamate transporter type 1 (VGluT1), a protein that is normally produced by glutamatergic neurons. This discovery prompted us to hypothesize that SN56 neurons may also co-express a glutamatergic phenotype which is important because glutamatergic neurons have been associated to the pathogenesis of neurological disorders such as Alzheimer's disease. To assess whether SN56 neurons express in fact both phenotypes, we conducted experiments in differentiated and no differentiated SN56 cell, to confirm the expression of glutamatergic phenotype, by qPCR, western blotting and Immunocytochemistry assay. The cells are cultured in an incubator gassed with $5 \% \mathrm{CO} 2$ at $37^{\circ} \mathrm{C}$. After differentiation for 3-5 days with cAMP and retinoic acid, SN56 cells were prepared for qPCR, western blotting and immunocytochemistry. Cells were separated by each experiment, primary antibodies or primers against NMDA glutamate receptor subunit NR2B, VGluT1 and vesicular cholinergic transport (ChAT) how positive control were used to confirm our hypothesis,. Expression of these markers will indicate a glutamatergic phenotype. After secondary detection with appropriate fluorescently-labeled antibodies we confirmed that differentiated SN56 neurons express glutamate NR2B receptor subtype and the VGluT1 transporter in both post-synaptic and presynaptic structures respectively. Hence, these findings support our hypothesis that SN56 neurons can co-express both cholinergic and glutamatergic phenotype.
\end{abstract}

\section{INTRODUCTION}

The murine basal forebrain cholinergic cell line SN56.B5.G4 is derived from the fusion of septal neurons of the mouse postnatal day 21 septum and the murine neuroblastoma cell line N18TG2 (Hammond et al., 1986). These cells exhibit a cholinergic neuronal phenotype upon stimulation with membrane permeable dibutyryl cAMP (dbcAMP) and all-trans-retinoic acid (Blusztajn et al., 1992; Jankowska et al., 1997; Pedersen et al., 1995) and nerve growth factor (Nilbratt et al., 2007). Cholinergic properties include: increased synthesis of acethylcholine (Ach), enhanced activity of choline acetyltransferase (ChAT), spontaneous and depolarization-evoked ACh release (Blusztajn et al., 1992; Jankowska et al., 1997; Pedersen et al., 1995), upregulation of vesicular acetylcholine transporter (VAChT) gene expression (Berse and Blusztajn, 1995), increased expression of different nicotinic acetylcholine receptor (nAChR) subtypes (Nilbratt et al., 2007) and several morphological features of neurons (neurite extentions, neurofilament protein immunoreactivity, puncta adherens, neuritic varicosities, vesicles) (Hammond et al., 1986; Hammond et al., 1990). Indeed, cholinergic

\footnotetext{
${ }^{1}$ Department of Biological Sciences at the University of Texas at Brownsville/Texas Southmost College, Brownsville, Texas 78520 USA.

${ }^{2}$ The Center for Biomedical Studies
} 
SN56 cells have been used as an "in vitro" model to investigate the pathogenesis of neurological disorders (Colom et al., 1998; Guerra et al., 2004; Heinitz et al., 2006; Jankowska-Kulawy et al., 2008; Joerchel et al., 2008; Marin et al., 2003; Pedersen et al., 1996; Szutowicz et al., 2006), specifically Alzheimer's disease (AD) which is characterized by cholinergic dysfunction and progressive basal forebrain cell loss (Mufson et al., 2008). The SN56 cell line posses cholinergic characteristics that make it a useful model for studying neuronal differentiation. This cell line, when treated with Retinoic Acid and cAMP, stops dividing and terminally differentiates into neurons; therefore, it makes it into an ideal cell line to study neuronal function. It is not clear whether these cells form excitatory glutamatergic synapses. In this study, we investigate this problem by performing electrophysiology, calcium imaging, qPCR and immunocytochemistry and co-localization analysis using specific primer and antibodies against a marker of glutamatergic synapses. The antibodies work while investigating the excitatory synapses expressing glutamatergic markers.

Our hypothesis is that with primary antibodies receptive to glutamatergic synapses, we will be able to determine if SN56 hybrid neurons express a glutamatergic phenotype. We will investigate the expression of glutamatergic markers including vesicular glutamate transporter1 (VGluT1) and glutamate receptor subunit epsilon-2 (NR2B) in SN56 Cells.

\section{MATERIALS AND METhODS}

\section{Cell Culture}

SN56 cells are a mouse cholinergic septal neuronal cell line (SN56.B5.G4) (Hammond et al., 1986; Hammond et al., 1990) previously shown to express ChAT (Blusztajn et al., 1992; Lee et al., 1990) that was generously provided by Bruce Wainer (Department of Pathology, Emory University School of Medicine, Atlanta, GA). The cells were maintained at $37^{\circ} \mathrm{C}$ in a humidified atmosphere of $5 \%$ $\mathrm{CO}_{2}$ in Dulbecco-Modified Eagle Media (DMEM, Sigma-Aldrich, Saint Louis, USA) supplemented with $10 \%$ fetal bovine serum and penicillinstreptomycin. The SN56 cells were passed at 1:10 every 4 days. To induce differentiation, SN56 cells were cultured in serum-free DMEM supplemented with $1 \mathrm{mM}$ dibutyryl cyclic AMP (dbcAMP) for 24 ,
48, 72 and 96 hours. SN56 cells were plated at the density of $\sim 1 \times 10^{6}$ per $60 \mathrm{~mm}$ diameter plate or 15000 cells on coverslip-lysine of 12 round diameter were grown for 2 days to subconfluency in Dulbecco's modified Eagle's medium (DMEM) containing $10 \%$ fetal bovine serum with $1 \mathrm{mM}$ glutamine and $100 \mathrm{ug} / \mathrm{ml}$ penicillin/streptomycin per $1 \mathrm{ml}$ at $37^{\circ} \mathrm{C}$ in atmosphere of $95 \%$ air and $5 \% \mathrm{CO}_{2}$. The cells were differentiated by $1,2,3$ and 4 days with $1 \mathrm{mM}$ ibutyryl-cAMP (cAMP)/1uM all trans-Retinoic acid (RA), or no-differentiated (control)

\section{Immunocytochemistry}

Following the plating of both differentiated (using RA and cAMP) and non-differentiated SN56 cells, the medium was removed and cells were fixed for 15 min with $4 \%$ paraformaldehyde/PBS followed by 3 PBS washes. Antibodies(Ab) were added: mouse monoclonal Ab 75-097, (NR2B), rabbit polyclonal Ab 32942 (NMDA), and guinea pig polyclonal Ab 5905 (vGlut1). Then, they were left to incubate overnight. After washing the cells three times with PBS they are exposed to corresponding secondary antibodies. Finally, the cells are washed three times with PBS and mounted to a slide prior to viewing. Imaging was performed using laser scanning confocal microscope in an Olympus IX81 inverted microscope.

3. qPCR. Real-time PCR reactions were carried out in a StepOne ${ }^{\mathrm{TM}}$ Real-Time PCR System using the SYBR Green I chemistry and primers for vGlut1, mGlu1/5, NR2B and nAChR previously validated in end-point PCR assays. The data was collected using OneStep Software and relative quantification was performed using the comparative threshold (CT) method after determining the CT values for reference $(G A P D H)$ and target genes.

4. Calcium Imaging Intracellular $\mathrm{Ca}^{2+}$ measurements using Fluo-4 Direct Calcium Assay Kits (invitrogen) in differentiated SN56 cells in coverslip, were treatment with $0.5 \mathrm{uM}$ TTX, $10 \mathrm{uM}$ gabazine, 50uM AP5 and 30uM CNQX. Cells were loaded with fluo-4 AM $\left(10 \mu \mathrm{M}\right.$ for 20 minutes at $\left.30^{\circ} \mathrm{C}\right)$. Cells were treated with $1 \mu \mathrm{M}$ probenesic at time zero and then imaged 15, 30, 65 and 75 seconds after stimulation. Positive control was used ACSF

\section{RESULTS AND CONCLUSION}

Analysis revealed that the SN56 cell line does demonstrate the co-existence of the pre-synaptic 
Vesicular Glutamate Transporter 1 (vGlut1) with the post-synaptic Glutamate Receptor Subunit Epsilon-2 (NR2B) and the metabotropic glutamate $1 / 5$. The calcium imaging confirm the previous results electrophysiological, faster action potential (see sample) can be blocked with AP5/CNQX. In addition the ratio the expression in differentiated cells, the vGLU1 is 6 fold more when compared with mGlu1/5, NR2B and nAChR in no differentiated cells.

This cell line model will now be used to further investigate drugs that modulate excitatory glutamate transmission along with cholinergic transmission with potential implications for understanding the basic mechanisms of epilepsy and other neurological disorders.

\section{Acknowledgments}

This work was supported by grants from LSAMP and National Institutes of Health as follows: NS06395003, 3SC1NS063950-03S1 (ARRA), P20MD001091, P20MD000161 to Dr. Garrido-Sanabria by the National Institute of Neurological Disorders., ARRA 3R25GM065925-06S1

Electrophysiological characterization of no differentiated and differentiated DN56 cells

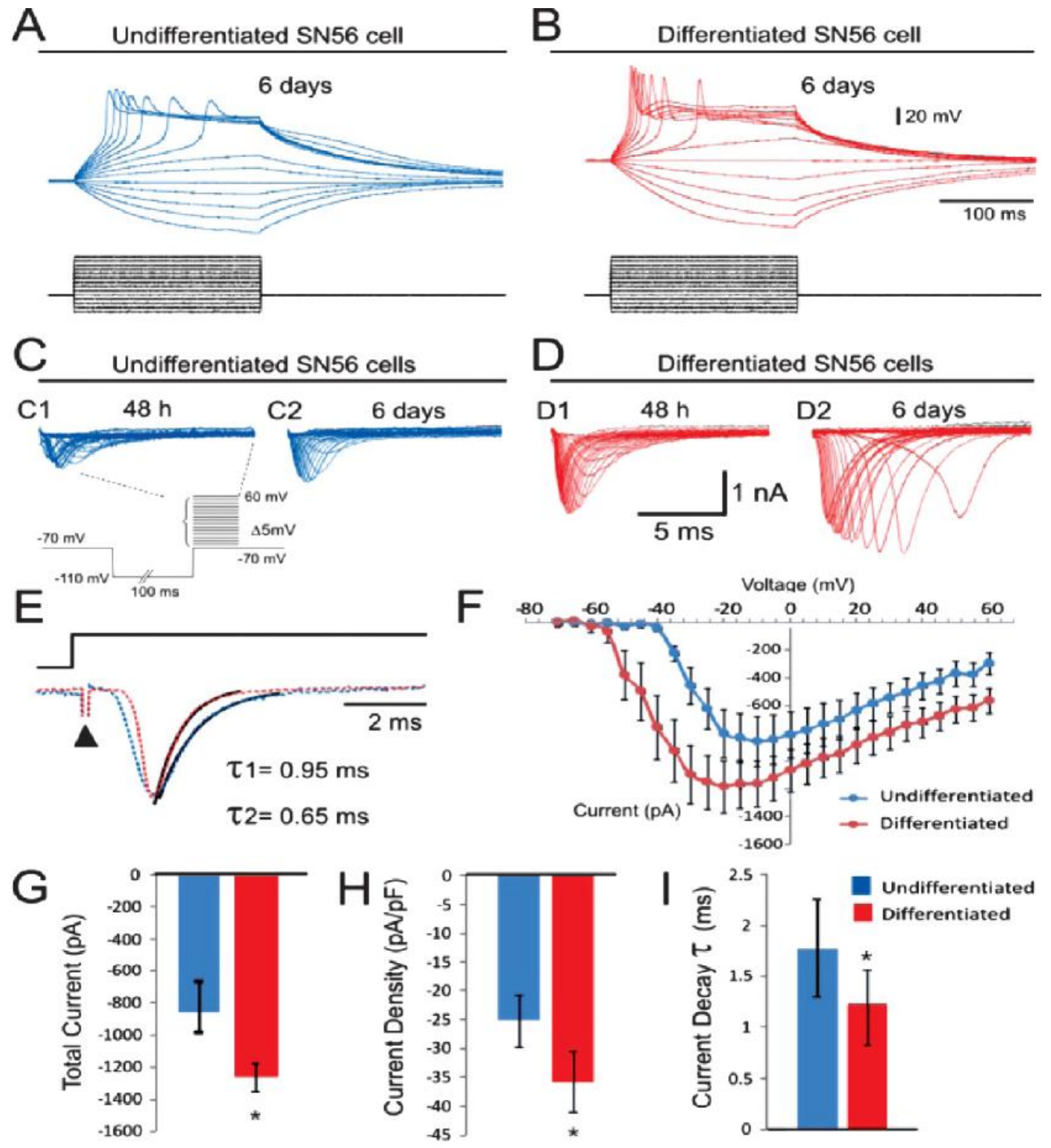

Figure 1. Electrophysiological characterization of no differentiated and differentiated DN56 cells. A. Current clamp recordings of undifferentiated cells shows wide action potentials in response to electrical stimulation 
(square current steps, below). B. Differentiated neuron exhibited faster action potential in response to similar stimulation protocol. C and D. Voltage-clamp recordings revealed small sodium current in undifferentiated cells ( $\mathbf{C 1}$ and $\mathbf{C 2}$ ) while differentiated neurons exhibited large sodium currents. E. Analysis of the current activation kinetics shows that sodium currents in differentiated cells have faster rising and decay phases (E) and are activated at lower membrane potential (F). G. Statistical analysis showing a significant increase in the amplitude of the total sodium current (undiff: $-848 \pm 85 \mathrm{pA}, \mathrm{n}=8$ compared to diff: $-1264.1 \pm 65 \mathrm{pA}, \mathrm{n}=10$, $*$ Student t-test, $P<0.05$ ) and current density (normalized to the cell capacitance) (undiff: $-25.0 \pm 5.5 \mathrm{pA} / \mathrm{pF}$ compared to diff: $-35.8 \pm 6.7 \mathrm{pA} / \mathrm{pF}, *$ Student t-test, $P<0.05$ ). Time constant of activation was also faster in differentiated cells (Student t-test, $\mathrm{p}<0.05$ ).

Immunocytochemistry for Glutamate Vesicle Transporter (vGlut1) and Glutamate Receptor (NR2B) on Differentiated SN56 Cells
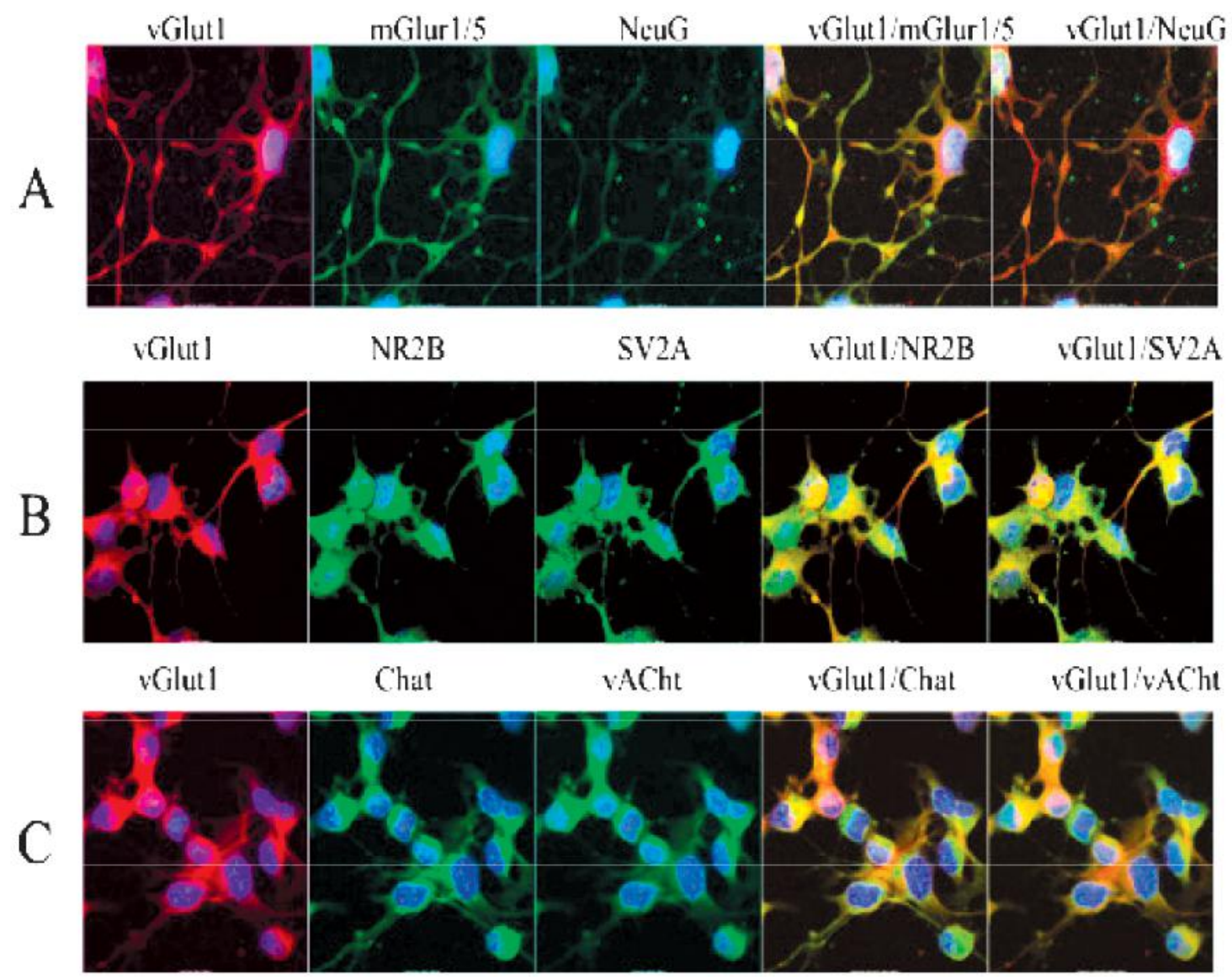

Figure 2: (A) Represents the validation immunocytochemistry of the polyclonal antibody vesicle transporter of glutamate 1 (vGlut1) (CY5 channel: panel A\&B) [1/500 $\mathrm{mg} / \mathrm{ml}]$ and monoclonal antibody of glutamate receptor subunit e2 (NR2B) (green channel: panel A\&B) $[1 / 100 \mathrm{mg} / \mathrm{ml}]$ in non-differentiated SN56 cells. (B) Demonstrates the expression of vGlut1, NR2B, and NMDA (glutamate receptor) (red channel: Panel B) [1/500 $\mathrm{mg} / \mathrm{ml}$ ] in differentiated SN56 cells. Positive control panel C expression of Chat and vAChT in differentiated cells 
Co-localization of NMDA with vGlut1 and NR2B

DIC vGlut1 NR2B NMDR MERGE
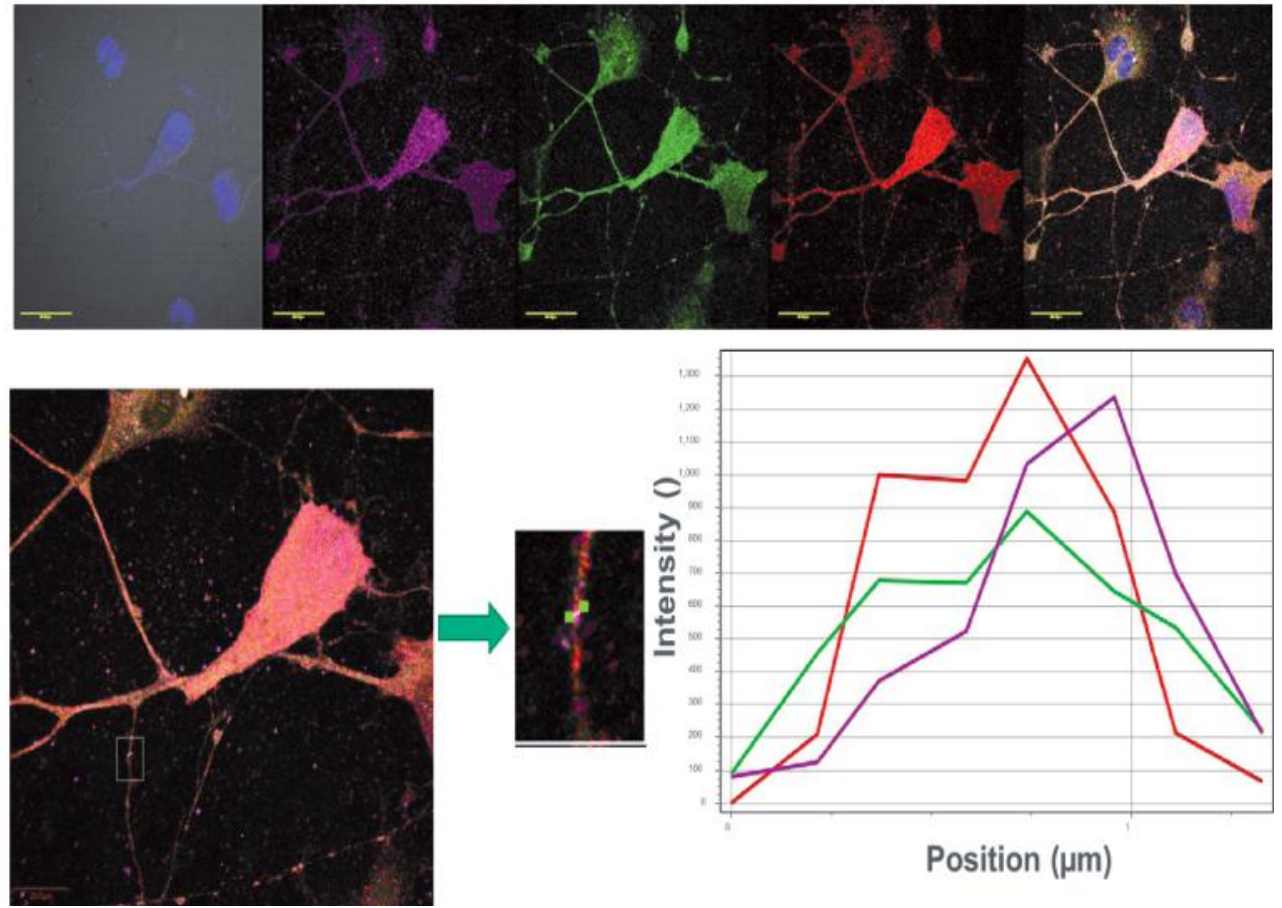

Figure 3: In order to confirm the co-localization of vGlut1 and NR2B the analysis of individual synapses was performed. This chart illustrates the presence of vGlut1, NMDA, and NR2B. NMDA, the glutamate receptor family in which NR2B belongs to (both post synaptic structures), peaks with NR2B. Next, you see the peak of vGlut1, a pre-synaptic transporter.

Glutamatergic expression in differentiated SN56 cells

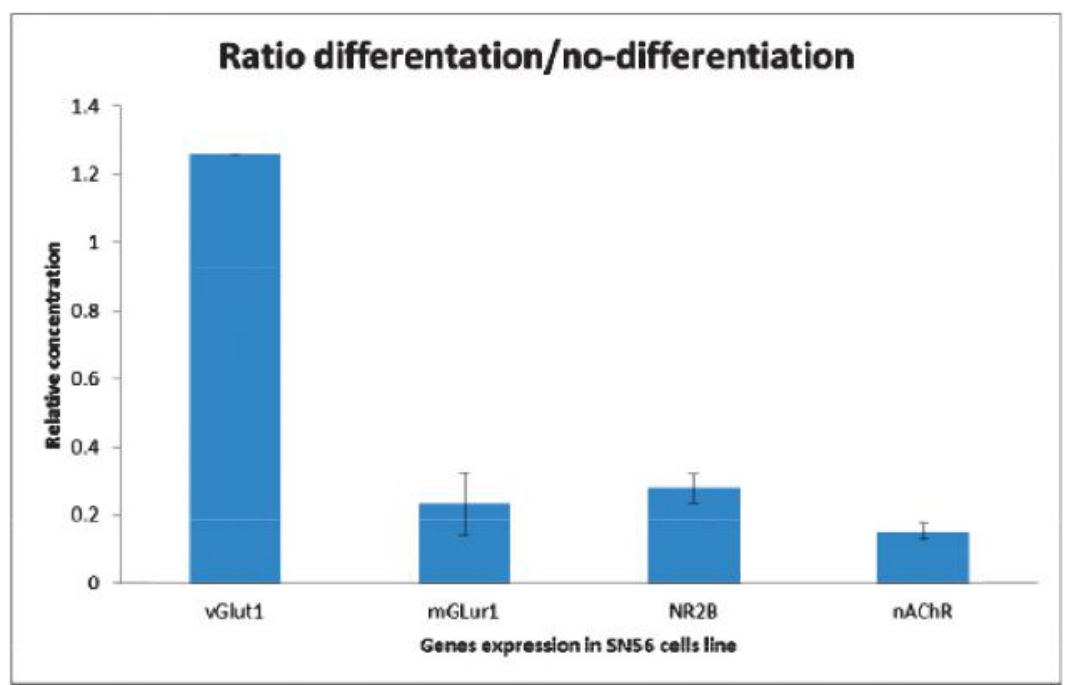

Figure 4. Relative gene expression analysis of vGlut1, mGlur1, NR2B and nAChR respectively was performed by the comparative CT qPCR method using primers (see the legend). Data (fold changes) is represented as arbitrary units normalized relative to gene expression control group. Analysis was performed in total RNA isolated from gyros dentate and converted to cDNA at SN56 cells differentiated and no-differentiated. Data represented as mean SD of normalized relative quantification index. 


\section{Primers:}

a. 5-tgcctcaggcttaagatgca-3 Forward

a. 5-caagcggagaacgactttca-3 Reverse

b. 5 -ccttgcaccgtctgatttggaggctg-3 Forward

b. 5-cagcgcgaaccacctgacg-3 Reverse

c. 5-cccagaccacaagcgetact-3 Forward c. 5-gcctccactgaccgaatctc-3 Reverse

d. 5-acggcgctttgccattgtc-3 Forward

d. 5-ccagcttcatgctgcagttc-3 Reverse

Legend:

a. vGlut1, b. mGlur1/5, c. NR2B, d. nAChR

Detection of individual action potentials with calcium imaging in differentiated SN56 cells

$\boldsymbol{\Lambda}$
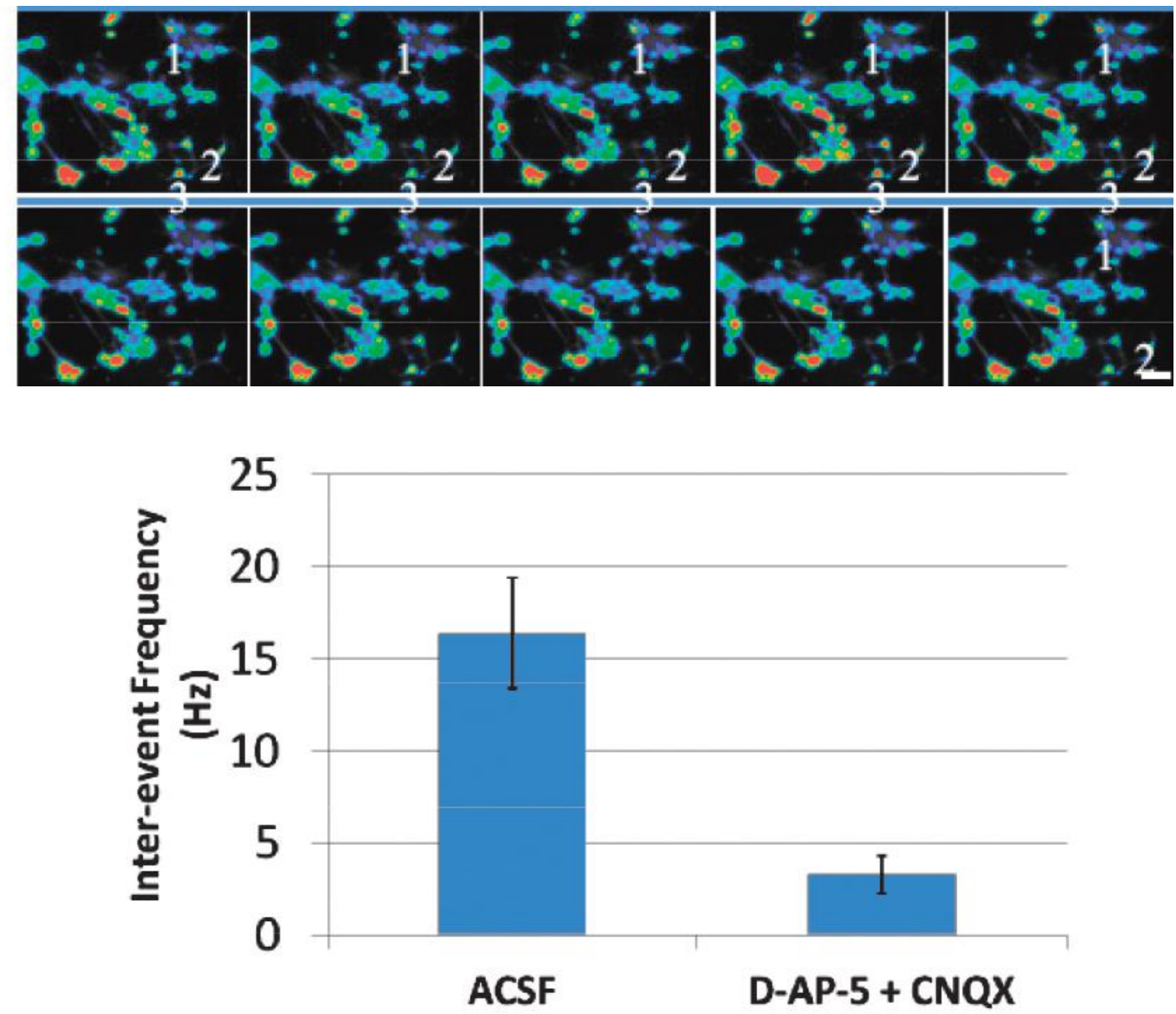

Figure 5: Spontaneous activity in SN56 cultured neurons is significantly reduced by blocking glutamatergic transmission. A. In normal ACSF, SN56 neurons exhibit spontaneous activity. Pseudocolored image sequence of changes in intracellular free $\mathrm{Ca} 2+$ in differentiated SN56 cells exhibiting spontaneous activity, monitored at 5 frame per second with $\mathrm{Ca} 2+$-sensitive dyes fluo-4 AM and fluorescence detection systems in Olympus BX61 microscope. A1. Fluorescence intensity changes over time in neurons 1,2 and 3 revealed spontaneous activity and synchronization of activity between neuron 2 (red) and 3 (blue). Wave and peaks represent increases in intracellular $\mathrm{Ca} 2+$ concentrations $(\mathrm{Ca} 2+$ transients or spikes) which are related to spontaneous action potentials in these neurons. B. Incubation of SN56 cell culture with antagonists of NMDA (AP-5, $50 \mathrm{uM}$ ) and AMPA receptors (CNQX, $20 \mathrm{uM}$ ) significantly reduced spontaneous activity. B1. Fluorescence intensity changes over time in neurons 1 and 2. C. Representative bar graph depicting pool data on changes in event $(\mathrm{Ca} 2+$ transients) frequency befor and after pharmacological block of NMDA and AMPA receptors. Paired Student t-test, $\mathrm{P}<0.001, \mathrm{n}=6)$. The images were pseudocolored according to fluorescence intensity, 
with red representing high $\mathrm{Ca} 2+$ concentrations and blue representing low $\mathrm{Ca} 2+$ concentrations. Scale bar for $\mathrm{A}$ and $\mathrm{B}=100$ microns.

\section{REFERENCES}

BERSE, B., Blusztajn, J.K., 1995. Coordinated upregulation of choline acetyltransferase and vesicular acetylcholine transporter gene expression by the retinoic acid receptor alpha, cAMP, and leukemia inhibitory factor/ciliary neurotrophic factor signaling pathways in a murine septal cell line. J Biol Chem. 270, 22101-4.

BIELARCZYK, H., Tomaszewicz, M., Madziar, B., Cwikowska, J., Pawelczyk, T., Szutowicz, A., 2003. Relationships between cholinergic phenotype and acetyl-CoA level in hybrid murine neuroblastoma cells of septal origin. J Neurosci Res. 73, 717-21.

BLUSZTAJN, J.K., Venturini, A., Jackson, D.A., Lee, H.J., Wainer, B.H., 1992. Acetylcholine synthesis and release is enhanced by dibutyryl cyclic AMP in a neuronal cell line derived from mouse septum. J Neurosci. 12, 793-9.

COLOM, L.V., Diaz, M.E., Beers, D.R., Neely, A., Xie, W.J., Appel, S.H., 1998. Role of potassium channels in amyloid-induced cell death. J Neurochem. 70, 1925-34.

GUERRA, B., Diaz, M., Alonso, R., Marin, R., 2004. Plasma membrane oestrogen receptor mediates neuroprotection against beta-amyloid toxicity through activation of Raf-1/MEK/ERK cascade in septal-derived cholinergic SN56 cells. J Neurochem. 91, 99-109.

HAMMOND, D.N., Wainer, B.H., Tonsgard, J.H., Heller, A., 1986. Neuronal properties of clonal hybrid cell lines derived from central cholinergic neurons. Science. 234, 1237-40.

HAMMOND, D.N., Lee, H.J., Tonsgard, J.H., Wainer, B.H., 1990. Development and characterization of clonal cell lines derived from septal cholinergic neurons. Brain Res. 512, 190-200.

HEINITZ, K., Beck, M., Schliebs, R., Perez-Polo, J.R., 2006. Toxicity mediated by soluble oli- gomers of beta-amyloid(1-42) on cholinergic SN56.B5.G4 cells. J Neurochem. 98, 1930-45.

JANKOWSKA-KULAWY, A., Gul-Hinc, S., Bielarczyk, H., Suszkiw, J.B., Pawelczyk, T., Dys, A., Szutowicz, A., 2008. Effects of lead on cholinergic SN56 neuroblastoma cells. Acta Neurobiol Exp (Wars). 68, 453-62.

JANKOWSKA, A., Blusztajn, J.K., Szutowicz, A., 1997. Activities of enzymes of acetyl-CoA and acetylcholine metabolism in SN56 hybrid cholinergic cell line differentiated by dibutyryl cyclic AMP and all-trans retinoic acid. Folia Neuropathol. 35, 247-9.

JOERCHEL, S., Raap, M., Bigl, M., Eschrich, K., Schliebs, R., 2008. Oligomeric beta-amyloid(1-42) induces the expression of Alzheimer disease-relevant proteins in cholinergic SN56.B5.G4 cells as revealed by proteomic analysis. Int J Dev Neurosci. 26, 301-8.

MUFSON, E.J., Counts, S.E., Perez, S.E., Ginsberg, S.D., 2008. Cholinergic system during the progression of Alzheimer's disease: therapeutic implications. Expert Rev Neurother. 8, 1703-18.

NILBRATT, M., Friberg, L., Mousavi, M., Marutle, A., Nordberg, A., 2007. Retinoic acid and nerve growth factor induce differential regulation of nicotinic acetylcholine receptor subunit expression in SN56 cells. J Neurosci Res. 85, 504-14.

PEDERSEN, W.A., Berse, B., Schuler, U., Wainer, B.H., Blusztajn, J.K., 1995. All-trans- and 9-cisretinoic acid enhance the cholinergic properties of a murine septal cell line: evidence that the effects are mediated by activation of retinoic acid receptor-alpha. J Neurochem. 65, 50-8.

PEDERSEN, W.A., Kloczewiak, M.A., Blusztajn, J.K., 1996. Amyloid beta-protein reduces acetylcholine synthesis in a cell line derived from cholinergic neurons of the basal forebrain. Proc Natl Acad Sci U S A. 93, 8068-71.

SZUTOWICZ, A., Bielarczyk, H., Gul, S., Ronowska, A., Pawelczyk, T., Jankowska-Kulawy, A., 2006. Phenotype-dependent susceptibility of cholinergic neuroblastoma cells to neurotoxic inputs. Metab Brain Dis. 21, 149-61. 